Essay

\title{
Writing Language: Composition, the Academy, and Work
}

\author{
Bruce Horner \\ Department of English, University of Louisville, Louisville, KY 40292, USA; b.horner@louisville.edu \\ Academic Editor: Ronald Strickland \\ Received: 4 December 2016; Accepted: 27 March 2017; Published: 30 March 2017
}

\begin{abstract}
This paper argues that while college composition courses are commonly charged with remediating students by providing them with the literacy skills they lack, they may instead be redefined as providing the occasion for rewriting language and knowledge. By bringing to the fore the dependence of language and knowledge on the labor of writing, a pedagogy of recursion, mediation, and translation of knowledge through writing and revision counters neoliberalism's commodification of knowledge and language, and offers an alternative justification for continuing education as the occasion for students to remediate language and knowledge through writing.
\end{abstract}

Keywords: remedial education; writing pedagogy; transfer; translation; English as a Lingua Franca; knowledge mobilization; language commodification; neoliberal university

\section{Introduction}

Composition has long carried a vocational charge within the university: to provide students with the skill to produce writing appropriate to meet the demands of academic disciplinary coursework and future employment. Those of us affiliated with the field of composition have both benefited from and long chafed under that charge. On the one hand, it has justified at least a minimum of support from the higher educational administration to make sure that students are in fact equipped with the writing skills requisite to meeting the demands of their academic courses and their future workplaces (Trimbur 1991). On the other hand, precisely because that support is based on what appears to be a purely vocational, if not remedial, need, composition as a field of study carries with it the stigma of lacking legitimate academic disciplinary status (Crowley 1998). The assumption has long been that students admitted to postsecondary education should already know how to write, and that composition courses have at best a remedial, and ideally temporary, function in teaching students what, by rights, they should already know how to do and that, in fact, is a relatively simple, even mechanical matter. Accordingly, composition programs-the courses and writing centers and instructors and the administrative apparatus to oversee all these-have always been kept on a tight financial leash due to the assumption that in some putative future return to a putative glorious past, the work of teaching composition will no longer be necessary; students will have learned how to write in primary and secondary school, and will bring that knowledge to college (Soliday 2002; Rose 1985). As the current argot puts it, they will graduate from high school "college-ready". This is at least one justification for the overwhelming reliance of most R1 universities on adjunct labor rather than tenure-line faculty to staff composition courses: it would be foolish to make permanent hires to fill what is believed, claimed, or hoped to be a temporary literacy crisis (Crowley 1995).

The history of what has been called the "abolitionist" movement within composition illustrates this dilemma. In that history, at least some composition scholars have advocated abolishing the course that has largely defined the field of composition - the universally required first-year undergraduate writing course-insofar as it tethers the identity of composition scholars, teachers, and the field to 
the status of first-year undergraduate students and the task of their remediation and of meeting "student needs", thereby preventing composition from achieving professional academic institutional disciplinary status as, in fact, a legitimate academic discipline (Crowley 1995; Dobrin 2011). Meanwhile, other composition scholars, drawing on studies of situated learning, have denied the existence of general writing skills that might, in fact, be taught in a first-year writing course and transfer to other disciplines and workplaces. They conclude, in light of this, that the only recourse for composition is to offer discipline- and workplace-specific writing instruction, in the form of writing in the disciplines courses and courses in professional (e.g., business, technical, scientific, legal) writing (see, for example, (Petraglia 1995; Smit 2004)).

It is worth noting that both such kinds of abolitionist arguments assume a transmission model of pedagogy in which students are introduced to specific forms of writing and trained in producing these. They differ only in the value attached to the kind of knowledge transmission to be attempted and in the kind of knowledge transmission that is imagined to be possible or needed: general writing skills or discipline- and workplace-specific writing skills. In this respect, abolitionists are largely in agreement with most of those who otherwise reject the abolitionist call, who simply differ from the abolitionists on the question of what kind of knowledge transmission is possible and necessary-general writing or disciplinary- and workplace-specific writing. So, for example, we can see this agreement operating in converse arguments to extend, and not merely maintain, the curriculum of composition to include forms of writing made possible by new communication technologies (e.g., (Yancey 2004; Selfe 2009; Alexander and Rhodes 2014)). In such arguments, attending to forms of writing deploying technologies other than alphabetic print on paper is now requisite to communication under globalization. As Cynthia Selfe explains,

[T]he inclusion of multiple modes of rhetorical expression represents a simple acknowledgment that a literacy education focused solely on writing will produce citizens with an overly narrow and exclusionary understanding of the world and the variety of audiences who will read and respond to their work. In the twenty-first century, we live in an increasingly globalized world where people speak different languages, come from different cultures, learn and make meaning in different media contexts and with different expressive modalities. In such an environment, [...] literate citizens, increasingly, need to make use of all semiotic channels to communicate effectively among different groups and for different purposes (Selfe 2010, p. 607).

Such arguments invoke the same "discourse of student need" as previous arguments justifying composition courses, merely updating what that need is thought to be that is to be met, on the basis of changes to communication technologies and the range of audiences to whom it is imagined students will aim to "communicate effectively" in the current century. Thus, in addition to transmitting the skills of using conventional technologies of academic writing (paper and pen, or word processing software), it is argued that we must now transmit skills in writing using other technologies and taking other forms (e.g., producing websites).

The global spread of English and the continued dominance of English-only monolingualist ideology has kept comparable arguments for extending the range of languages in which students learn to write to a minimum. Instead, most commonly, English itself is identified as having achieved the status of the global lingua franca, and this is used to justify the transmission of knowledge of English worldwide to facilitate the worldwide transmission of knowledge (Guardiano et al. 2007). Granted, there remains a strong tradition in language education advocating some form of multilingualism-often conflated with plurilingualism or translingualism - as an alternative means of allowing for that same worldwide communication of knowledge (see (Cameron 2002; Dor 2004; Flores 2013; Ganahl 2001; Kubota 2016; Kramsch 1998)). What aligns all such arguments with those advocating the extension of the range of writing technologies to be taught is their treatment of languages, and language skills, no less than writing technologies, as commodities to be transmitted: (global) English, or Standard 
Written English, or a combination of English and other languages and skill in translating between and among them.

In the remainder of this essay, I focus on those arguments concerning language insofar as they betray the ideological character of the claims being made and, thereby, the weaknesses on which a pedagogy combatting that ideology can be directed. Specifically, against a view of (written) language as, ideally, a smooth, friction-free conduit for the communication of ideas and knowledge, exemplified by the insistent focus on clarity of expression in writing (Barnard 2010), the study of writing and its teaching demonstrates the necessity of readers' and writers' labor to the ongoing production and revision of language. For language, rather than existing prior to writing as an environment that writers merely write (with)in, is the ongoing outcome of writers' labor: that which they write, and rewrite, with every stroke of the pen or keyboard (as do speakers with every utterance). Thus writers are responsible for the ongoing production and revision of language. Writing courses, then, rather than being understood as a means to remediate writers, can instead be understood as providing occasions for the remediation of language, a task that, of course, never ends insofar as the human condition itself is an ongoing outcome of such labor. However, this shift in the conception of writing courses requires a rethinking of key terms in writing and pedagogy: transfer, translation, and transmission, as well as, of course, language and writing itself.

\section{Transfer, Translation, Transmission, and Writing Language}

Issues of transfer and transmission permeate questions of writing and writing pedagogy, and in two ways (see (Yancey et al. 2014; Nowacek 2011; DePalma and Ringer 2011)). Like other school subjects, writing pedagogy is concerned with how the knowledge to be learned is to be transmitted, and with the transferability of that knowledge across contexts. So, for example, writing teachers have long concerned themselves with how the sequencing of writing assignments might best introduce students to and increase their fluency in producing writing that deploys different "modes" of expression (exposition, narration, description, argument) or that addresses different rhetorical situations, or how an assignment sequence might lead students through a "natural" developmental progression from simpler to more complex writing challenges or from more "egocentric" to "transactional" cognitive tasks. The assumption underlying most of these arguments, however, is that the forms of writing to be taught, and the order in which skill in producing them occurs, are set. However much there may be disagreement about those forms and that order, the ultimate focus has remained on how best to transmit writing skills (see (Rankin 1990)). However, writing courses are distinguished from most other school subjects in that in writing courses, what is to be learned is itself also understood to be a means of knowledge transmission and transfer. Two issues immediately arise here: the status of the knowledge to be gained, and the relationship of that knowledge to the means of its mobilization within and across contexts. These issues are then further complicated by a third factor: the status of the language written and the role that writing language plays in the status of the knowledge to be transmitted and its mobilization.

The issue of language helpfully brings what might otherwise be understood as immaterial, entirely theoretical questions of epistemology back to the material social realm by recasting questions of transfer and transmission as questions of translation, with all the problematics of material social differences that translation brings. For, contrary to what neoliberalism would have us believe, to translate is to recast, and thereby change, what is translated through the process of translation. Likewise, knowledge, in being transferred through writing, is thereby transformed in its move to a different context. As Rebecca Nowacek puts it, transfer is a matter of recontextualization-that is to say, both a change to the knowledge being transferred through its relocation to a different context, and a change to that context through the introduction of that knowledge to it (Nowacek 2011). As Michael DePalma and Jeffrey Ringer observe in arguing for an "adaptive" model of transfer, transfer changes both the knowledge transferred and the context to which it is transferred. Students, like all writers, are thus "both users and transformers of writing knowledge and writing contexts" (DePalma and Ringer 2011, p. 142). 
DePalma and Ringer's notion of "adaptive" transfer challenges the stability of both the knowledge to be transmitted and transferred and, as well, the contexts to which it is brought. Knowledge and the context appear from these notions of transfer to be the always emerging outcomes of acts of writing: we write and, in so doing, recontextualize both the knowledge we write and the context of that writing into (new) being. However, language theorists offer a further destabilization to this model by positing languages as themselves the emerging outcome of practices. Just as knowledge is, from the adaptive transfer model, located in practices, and hence in time as well as space, rather than being posited as outside the material social realm, so language is by theorists conceptualized as a "local practice" (Pennycook 2010), its nature always emergent as it is continually subjected to reproduction and revision through practices of its users (Calvet 2006).

Two consequences for language follow from its location in practice: first, it is dependent in its definition, continuation, and character on its users; and second, it is inevitably different by virtue of its location in time. As Pennycook observes, just as one can never step into the same river twice, given the inevitable difference of the river and the stepper produced by time, so language, including seemingly exact repetitions of utterances, are inherently different by virtue of their location in time. Difference, from this perspective, rather than constituting a deviation from a norm of sameness in language, is itself the norm, and the perception of sameness a characteristic requiring explanation. It is in this sense that, as Pennycook puts it, English itself is a language "always in translation" even when no other languages (as conventionally demarcated) appear to be involved, for even exact reiterations of English introduce difference to the utterance and its meaning by virtue of their changed temporal location (Pennycook 2008). Writers, even when writing the same thing in the "same" language, introduce difference, and hence rewrite the language (Lu and Horner 2013).

This destabilization of language, knowledge, and writing knowledge through their relocation in time as the interconnected, always emergent and always different outcomes of practices is directly at odds with notions of translation as a means of efficient and reliable communication, also known as transmission, of information, notions that neoliberalism requires of an "information" economy. As translation scholar Michael Cronin notes, translation is "a constituent, integral part of how the phenomenon [of a globalised information economy] both operates and makes sense of itself" (Cronin 2003, p. 34). For "[i]f information is often hailed as the basic raw material of the new economy and significant economic gains are to be made from the production of goods with a high cognitive content, then it follows that language itself is not only a key factor in the expression of that information but it is also a crucial means in accessing the information" (Cronin 2003, p. 16).

The problem with this neoliberalist understanding of translation is not merely with its allegiance to the profit motive or the disproportionality of the effects of the new economy it imposes on various populations, but with the model of translation in which it puts its faith. For as scholars of translation have shown, the notion of equivalence heralded as an ideal for translation on which the neoliberalist economy depends fails to hold up under scrutiny. Instead, that which is translated is inevitably transformed in the process of "its" translation, and what counts as a legitimate translation is contingent on sociopolitical interests. Even in those instances where faithful translation-in the sense of exact equivalence-is attempted, friction enters that "charges and changes" what is moved (Tsing 2005). In addition, finally, as already discussed, even reiterations in the same language introduce difference by virtue of the different temporal location into which each iteration is "translated".

I am suggesting, then, that we grant too much credit to the tale neoliberalism tells of itself and its doings, overlooking the flaws in its claims. Instead, we need to take J. K. Gibson-Graham's advice by "cutting capitalism down to size (theoretically) and refusing to endow it with excessive power" (Gibson-Graham 2006, p. xxiv). One way to do so is to challenge the notions of knowledge, writing, and language on which its economic model depends. Insofar as that economic model assigns higher education the restricted role of producing and transmitting economically viable knowledge, including communication skills, for prospective workers, as students/customers/clients, to consume, we can cut that model down to size theoretically by (1) bringing into visibility the inevitable differences in 
what are claimed to be equivalent utterances; (2) highlighting the dependence of knowledge and the language assigned as its ostensible conduit on the continuing concrete labor of writers and readers; (3) re-imagining, and re-casting, the site of pedagogy as the occasion not for the transmission of what are claimed to be stable knowledge and skills in writing but, instead, for the rewriting of knowledge and language by students, in concert with teachers: composing (and revising) writing, language, and knowledge, and thereby contributing to sustaining them, through the labor of composition.

\section{English, Englishes, and English as a Lingua Franca}

Ample evidence for the false claims of neoliberalism is provided in the status of English itself as a stable, discrete, and internally uniform entity knowledge of which the neoliberal university is to transmit to its students. At the very least, "English" is more aptly understood in pluralized form as Englishes, including China English, Australian English, Nigerian English, etc., as scholarship on world Englishes has amply demonstrated (see for example (Brutt-Griffler 2002; Kachru 1990)). However, further, English in its practice as a global lingua franca is not merely plural but in constant flux. This is the finding of scholarship on English as a lingua franca. While initially that scholarship appeared to be directed toward identifying English as a Lingua Franca (ELF) as a particular variety of English, studies have made it increasingly clear that ELF is, instead, a function (Friedrich and Matsuda 2010) whose formal characteristics are under continuous revision, contingent on its specific occasions of use. Indeed, researchers find that "[ELF] never achieves a stable or even standardized form". ELF, they find, "is intersubjectively constructed in each specific context of interaction...negotiated by each set of speakers for their purposes" ((Meierkord 2004, p. 129); qtd. in (Canagarajah 2007a, p. 926)). In fact, as Nicos Sifakis has explained, "[V]ariability in the communication between different [ELF speakers] renders any attempt at codifying [and teaching] the various uses of English in [ELF] situations difficult, since we would have to know in advance many things that are situation-specific and user-dependent" (Sifakis 2006, p. 155) —and not just the forms ELF takes, but "even the enabling pragmatic strategies do not have to be the same" for its speakers (Canagarajah 2007a, p. 926). In other words, we cannot assume a fixed set of conditions, contexts, or language use to define ELF, but must instead accept the emergent and co-constitutive character of all these. ${ }^{1}$

Further, because ELF is reconstituted in each instance of its practice, we cannot identify a particular set of practices with "competence" in it. Instead, competence itself is in need of redefinition. For, as Juliane House puts it, "[A] lingua franca speaker is not per definitionem not fully competent in the part of his or her linguistic knowledge under study" (House 2003). Or as Canagarajah iterates, "all users of [ELF] have native competence of [ELF]" (Canagarajah 2007a). Thus, teachers can assume neither the need to move students toward a state of "competence" in ELF nor the stability of that state itself. The emphasis for teachers would thus need to be not on giving students a specific set of forms to use but on "the socio-pragmatic functions of language choice" (House 2003, p. 588), and on "interaction strategies" (Canagarajah 2007b, p. 96). The attitudes necessary for effective engagement with ELF, these studies show, include "tolerance for variation, and a focus on mutual cooperation" (Rubdy and Saraceni 2006, p. 12), an understanding that "variation from the norm...is itself likely to be 'the norm"' (Rubdy and Saraceni 2006, p. 12), an orientation to issues of "process" rather than "product"; humility and a willingness to negotiate meaning, including the practice of "letting ambiguities pass" on the assumption that they will eventually be resolved (Canagarajah 2006a, pp. 204-5; Canagarajah 2007a, pp. 926, 931; Canagarajah 2006b, pp. 592-93); and a recognition of language "as changing rather than static" and not just "context-appropriate but context-transforming" ((Canagarajah 2006a, p. 211); cf. (Khubchandani 1998, pp. 20-21)). ${ }^{2}$

1 For a more extended analysis of ELF as model for composition, see (Horner and Lu 2012).

See (Horner 2016), Chapter Two. 


\section{Rewriting English from the Neoliberal University}

Much of the research on ELF focuses on spoken rather than written interactions. However, if we set aside the textualist bias that identifies the work of writing purely with the printed text, imagined to operate as the autonomous conduit of meaning to readers, we can recognize the same processes of negotiation of language and meaning operating in writers' and readers' interactions with and revisions to these (Horner forthcoming). That is, against neoliberalist claims to writing as transmission by friction-free translation of information, we can insist on, demonstrate, and explore the necessity and effects of readers' and writers' concrete labor, in writing and reading, to the ongoing production and meaning and revision of language-labor that is occluded in the commodification of writing, language, and knowledge but remains nonetheless. The presence and effect and necessity of that labor can be made apparent through the introduction of recursion, mediation, and translation into course design.

Here is where a course on writing language can work from the neoliberal university rather than merely against it. One feature of the neoliberalist charge assigned to higher education that distinguishes it from fordist models is the assumption of the need for continual re-education and reskilling of workers insofar as extant knowledge and skills are assumed to be vulnerable to supercession by demands for new knowledge and skills, hence the emphasis on higher education as continuing, or recurring, rather than the fordist model of higher education representing at most a one-time stage in individuals' linear, sequential career trajectory from schooling to beginning employment and (hopefully) advancement in the same workplace or career until retirement. That is to say, neoliberalism offers a twist on the "myth of transience" of the "literacy crisis" that has hobbled the status and working conditions of composition programs. Rather than assuming an eventual return to a mythical yesteryear when students admitted to postsecondary education were all already fully literate (hence the transience of the need to remediate those students), neoliberalism posits that whatever literacy skills students may possess at any given time will quickly lose value as new literacy skills come to be in demand and their existing skills become obsolete, particularly as a consequence of "globalization" and "innovation" in communication technologies. Thus the ability to write a "paper" may no longer be sufficient for workers expected to produce websites or participate in the Twitterverse. Instead, what is needed are "just in time" courses designed to provide workers "just in time" with emerging but presumably also ephemeral new writing skills to produce new forms of writing.

Such a model retains the "transmission" conception of pedagogy, but substitutes for what had been imagined to be a monolithic and unchanging writing knowledge a diverse and ever-changing writing knowledge to be transmitted, hence the need for continuing education to "keep up". In this framing, all student/worker/writers are in need of periodic remediation insofar as any knowledge of writing they may have acquired is assumed to be inevitably vulnerable to becoming obsolete as the demand for new forms of writing knowledge replace demands for earlier forms. Further, such a framing retains a transmission model of writing: the form that writing takes changes, but its function as (ideally) a friction-free conduit remains constant.

However, of course the same concerns of transfer would apply: it is unclear that any (new) writing skills learned in school settings would, in fact, transfer any more than the putative general skill in writing that composition has long been charged with transmitting transfers across contexts. In other words, the neoliberal call for frequent retooling maintains faith in the stability and the transferability of the "tools" transmitted. Like the latest generation of iPhones, each version of writing skills, it is assumed, would "work" until superseded by the next generation. What we have, then, in this neoliberal framing, is a mere pluralizing of the previous fordist model of production (which also, notoriously, incorporated the planned obsolescence of its products).

Thus, while the neoliberal university offers itself as the alternative to the traditional, fordist model of higher education, it instead constitutes merely a multiplication and tweaking of that model. An instructive parallel to this can be found in the emergence of programs in writing in the disciplines (WID) as an alternative to the program of a universally required first-year composition program. The claim made was that WID did away with the one-size-fits-all model of first-year composition, and 
that model's apparent treatment of writing, or at least academic writing, as a single, internally uniform monolith. It did so by acknowledging differences by discipline: chemistry writing, history writing, sociology writing, etc. However, this pluralization of academic writing into a plethora of disparate forms of academic writing retained the stability, internal uniformity, and discrete character of each of the many forms of disciplinary writing it acknowledged, producing what came to be critiqued as a flock of writing "utopias" (Mahala 1991)—idealized communities of discourse into which students were to be inducted and whose particular textual conventions they were to be taught to write within. Alternatively, disciplines may better be understood as located in their discursive practices as entities that students (and their teachers) do not so much write "in" but continually rewrite.

In short, while neoliberalism acknowledges the diversity in writing and knowledge, and even the ephemerality of these as new forms of writing and knowledge are demanded, it retains a sense of the stability of the individual forms of writing and knowledge that are to be transmitted. It accepts, in other words, the commodification of these, which occludes the necessity of concrete labor to their production and effects. The number of commodities is increased, but their status as commodities is not challenged.

\section{Teaching Writing as Recursion, Mediation, Translation}

Writing courses aimed at countering this commodification will need to find ways to bring out, in order to more fully engage, the continuing necessity of the concrete labor of reading and writing to the production of meaning - the friction, as it were, inherent to meaning production and struggle-that any commodification of knowledge elides. I offer three guiding principles for the design of any writing pedagogy aiming to accomplish this: recursion, mediation, and translation. By foregrounding the temporality of all acts of reading and writing, these principles foreground the dependence of meaning on the continuing concrete labor of writing and reading. By relocating reading and writing in time, as temporal acts, a writing pedagogy designed according to principles of recursion, mediation, and translation brings out the different in the purportedly same, and the same in the purportedly different. And in so doing, it recuperates the agency and responsibility exercised by all writers and readers in the kinds of writing and reading and meaning-making in which they engage in their work with language, and in sustaining and revising knowledge (its re-production) through their acts of writing and reading.

Students' role in knowledge (re)production is of course operant in all their work in all disciplines. A writing course simply accentuates that role through its focus on the mediation of knowledge effected through writing. However, to the extent that all courses deploy student writing and reading (including the study and interpretation of social and natural phenomena) as a significant measure of their work, the principles of recursion, mediation, and translation apply across disciplines. That said, I will focus here on what a writing course based on such principles might look like.

In one sense, recursion, mediation, and translation get at what is sometimes simply identified as revision: the need to return, again and again, to the "same" text, question, or phenomenon not so much to correct earlier misinterpretations but to produce an interpretation different than one's previous interpretation-different in time as well as space and therefore necessarily in perspective, however slight that difference might be. However, revision is more commonly understood, both by students and by many of their teachers, as simply an opportunity to correct or somehow "improve" the original, with the expectation that the correct (and thereby) improved version will then suffice. And, often enough, revisions are assigned as part of the "drafting" process, if not as punishment, then on the assumption that, ideally at least, no revision is necessary: students will "get it right" the first time (again, at least ideally). Certainly within a neoliberalist frame, a one-shot, one-time engagement would appear to be the most efficient model for knowledge production and transmission. And within that frame, language remains at best a commodity, a tool for that transmission.

Alternatively, from the argument I advance here, revision is understood as both inevitable and necessary, always, for all. For revision is not only a means of correcting misinterpretations-though this of course may be one consequence- but is also necessary to sustaining knowledge. An extreme 
example will illustrate: a student whose "revision" of an earlier paper reproduces exactly in wording and form the same student's earlier paper except in its date would, I submit, constitute a revision that contributed to the ongoing process of the sedimentation of knowledge represented by the reiteration of that particular formulation of that knowledge in the revised paper. As much as it might well, and quite understandably, be understood as simply "the same", it is in fact also different insofar as it represents a reiteration of what has already been said, and thereby contributes to, by confirming, that earlier formulation, rendering that earlier formulation as now something that has been reiterated.

This is not to condone such a practice but, rather, to recognize the agency and, importantly, responsibility of writers who might take up that practice for contributing to the further sedimentation of that formulation, which is now more deeply sedimented as a consequence of their reiteration of it. ${ }^{3}$ Any writers engaging in such reiterations can be held to account for their role in that sedimentation process. Of course, the immediate reaction of teachers to such a practice might well be to charge the student with either plagiarism or not doing any work. However, I submit it would be more productive to require the student to explain why $\mathrm{s} /$ he has chosen to reiterate what $\mathrm{s} /$ he (or someone else) has already written. And such a task, if it did not prompt a change in perspective, would nonetheless change the status of the knowledge by offering further confirmation of the legitimacy of the reiterated formulation.

As unlikely as the scenario sketched above may be, it is encouraged by assignments that simply call for a revision, which typically lead not to exact reiterations of previous work but, more insidiously, only slightly modified reiterations: a changed word here, different punctuation there-differences that make little difference. To avoid such responses, a course that, rather than asking for "revision", instead returns students periodically to the "same" text, question, or phenomenon after the student/writers have been considering another text, question, or phenomenon enables more productive revision through building recursion into the design of the course. For example, in the middle of the semester of a recent first-year writing course, I asked students to look again at Thomas Kuhn's article “The Historical Structure of Scientific Discovery" , which they had spent several weeks considering at the beginning of the term, after they had been reading and writing about notions of language and knowledge introduced by Haunani-Kay Trask's essay "From a Native Daughter", which challenges historians of Hawaii for promulgating views of native Hawaiian culture that failed to take into account native Hawaiian language, and that deploys a mixture of languages and genres into what otherwise appears to be a scholarly text (complete with footnotes and citations to scholarship) (Kuhn 1962; Trask 1987).

The work with Trask's essay thus offered students a means of recontextualizing Kuhn's own essay, leading to quite different questions, concerns, and perspectives on Kuhn from those they had originally brought to their reading of Kuhn's essay, not so much in contradiction to their earlier questions, concerns, and perspectives as in oblique relation to those. Their writing on Kuhn "post-Trask" thus might in some ways build on their previous writing while also pursuing quite different directions, and while quite explicitly considering Kuhn's essay in the context of Trask's (just as they had been unable to work with Trask outside the context of their earlier considerations of Kuhn). Building a return to previous work - here, Kuhn-into the design of the course accentuated (1) the normality of such recursion; (2) the mediation of knowledge-here, knowledge of Kuhn-by its continual re-contextualization; (3) the inevitability of engagements in translation of texts such as Kuhn's and the impossibility of producing an "equivalence" in writing of another text through, say, "summary" or "paraphrase" (Horner and Tetreault 2016), and hence the need for continual re-engagement with that text.

Elizabeth Rankin has called the design of sequences of assignments like the one I have just described "cumulative epistemic" to distinguish them from those that are non-hierarchical and

3 See (Lu and Horner 2013). 
serial-i.e., in which the order of the assignments is not significant-and also from those that are hierarchical and cumulative but which are designed to increase complexity only in terms of cognitive or formal development-say from shorter, "simpler" genres to more complex genres (Rankin 1990, pp. 130-31). For the "cumulative" effect of cumulative epistemic sequences is not so much to "build on" and build up a specific body of knowledge, skills, or understanding but, rather, to reinforce the location of any knowledge possessed in material social conditions as the ongoing product of the labor of mediation and translation as that knowledge gets re-articulated, and thereby transformed, through its writing. Even those articulations that appear to mirror, in some ways, previous articulations constitute, from the perspective I am advancing, a transformation insofar as these re-articulations confirm, and thereby further solidify, the validity of the previous articulations-as in my extreme hypothetical example discussed above.

In reinforcing the role of the concrete labor of writing and reading as a means of articulating knowledge, such a pedagogy counters the commodification of knowledge, which by definition occludes the dependence of knowledge on the concrete labor of its (re)articulation. And in countering such commodification of knowledge through attention to its continual reworking, courses following such a design pose an alternative justification for education, and continuing education: not to offer a one-time preparation for one-track careers through skills provision, nor to retool or reskill workers for the new demands of new work, but to rework knowledge itself, a task to which all can contribute and should have a right to participate in insofar as all have a stake in the outcome. Further, a composition course reworks not just knowledge, but language itself as something one does not simply write within but rewrites with each stroke of the pen or keyboard. In other words, whereas conventionally composition courses, fordist and post-fordist, have the aim of remediating students, the composition course I am imagining has as its aim the remediation of knowledge and language, a task that is by definition necessary and necessarily ongoing, and in which all can and should have the chance to participate. Rather than treating education as the occasion for gifting those students or the unemployed with the employment skills they (now) need, education can be understood as an occasion for making use of the resources the students themselves constitute, through their labor, to rework language and knowledge through their efforts at knowledge articulation in language through writing (and rewriting). Against neoliberalism's treatment of education as the means for individual economic advancement through skills acquisition, we can treat education as the occasion for work on and with the commons of language and knowledge, a project to which all of us can contribute and in which all of us have a stake.

Conflicts of Interest: The author declares no conflict of interest.

\section{References}

Alexander, Jonathan, and Jacqueline Rhodes. 2014. On Multimodality: New Media in Composition Studies. Urbana: National Council of Teachers of English Conference on College Composition and Communication.

Barnard, Ian. 2010. The Ruse of Clarity. College Composition and Communication 61: 434-51.

Brutt-Griffler, Janina. 2002. World English: A Study of Its Development. Clevedon: Multilingual Matters.

Cameron, Deborah. 2002. Globalization and the Teaching of 'Communication Skills'. In Globalization and Language Teaching. Edited by David Block and Deborah Cameron. Milton Park: Routledge, pp. 67-82.

Canagarajah, A. Suresh. 2006a. Negotiating the Local in English as a Lingua Franca. Annual Review of Applied Linguistics 26: 197-218. [CrossRef]

Canagarajah, A. Suresh. 2006b. The Place of World Englishes in Composition: Pluralization Continued. College Composition and Communication 57: 586-619.

Canagarajah, A. Suresh. 2007a. Lingua Franca English, Multilingual Communities, and Language Acquisition. Modern Language Journal 91: 923-39. [CrossRef]

Canagarajah, A. Suresh. 2007b. The Ecology of Global English. International Multilingual Research Journal 1: 89-100. [CrossRef]

Calvet, Louis-Jean. 2006. Towards an Ecology of World Languages. Translated by Andrew Brown. London: Polity. Cronin, Michael. 2003. Translation and Globalization. London: Routledge. 
Crowley, Sharon. 1995. Composition's Ethic of Service, the Universal Requirement, and the Discourse of Student Need. JAC 15: 227-40.

Crowley, Sharon. 1998. Composition in the University: Historical and Polemical Essays. Pittsburgh: University of Pittsburgh Press.

DePalma, Michael-John, and Jeffrey M. Ringer. 2011. Toward a Theory of Adaptive Transfer: Expanding Disciplinary Discussions of 'Transfer' in Second-Language Writing and Composition Studies. Journal of Second Language Writing 20: 134-47. [CrossRef]

Dobrin, Sidney. 2011. Postcomposition. Carbondale: Southern Illinois University Press.

Dor, Daniel. 2004. From Englishization to Imposed Multilingualism: Globalization, the Internet, and the Political Economy of the Linguistic Code. Public Culture 16: 97-118. [CrossRef]

Flores, Nelson. 2013. The Unexamined Relationship between Neoliberalism and Plurilingualism: A Cautionary Tale. TESOL Quarterly 47: 500-20. [CrossRef]

Friedrich, Patricia, and Aya Matsuda. 2010. When five words are not enough: A conceptual and terminological discussion of English as a lingua franca. International Multilingual Research Journal 4: 20-30. [CrossRef]

Ganahl, Rainer. 2001. Free Markets: Language, Commodification, and Art. Public Culture 13: 24-38. [CrossRef]

Gibson-Graham, Julie Katherine. 2006. The End of Capitalism (as We Knew It): A Feminist Critique of Political Economy, 2nd ed. Minneapolis: University of Minnesota Press.

Guardiano, Cristina, M. Elena Favilla, and Emilia Calaresu. 2007. Stereotypes about English as the Language of Science. AILA Review 20: 28-52.

Horner, Bruce, and Laura Tetreault. 2016. Translation as (Global) Writing. Composition Studies 44: 13-30.

Horner, Bruce, and Min-Zhan Lu. 2012. (Re)Writing English: Putting English in Translation. In English-A Changing Medium for Education. Edited by Constant Leung and Brian Street. Bristol: Multilingual Matters, pp. 59-78.

Horner, Bruce. 2016. Rewriting Composition: Terms of Exchange. Carbondale: Southern Illinois University Press.

Horner, Bruce. Forthcoming. Written Academic English as a Lingua Franca. In Routledge Handbook of English as a Lingua Franca. Edited by Jennifer Jenkins, Martin Dewey and Will Baker. London: Routledge, Forthcoming.

House, Juliane. 2003. English as a Lingua Franca: A Threat to Multilingualism? Journal of Sociolinguistics 7: 556-78. [CrossRef]

Kachru, Braj. 1990. The Alchemy of English: The Spread, Functions, and Models of Non-Native Englishes. Urbana: University of Illinois Press.

Khubchandani, Lachman M. 1998. A Plurilingual Ethos: A Peep into the Sociology of Language. Indian Journal of Applied Linguistics 24: 5-37.

Kramsch, Claire. 1998. The Privilege of the Intercultural Speaker. In Language Learning in Intercultural Perspective: Approaches Through Drama and Ethnography. Edited by Michael Byram and Michael Fleming. Cambridge: Cambridge University Press, pp. 16-31.

Kubota, Ryuko. 2016. The Multi/Plural Turn, Postcolonial Theory, and Neoliberal Multiculturalism: Complicities and Implications for Applied Linguistics. Applied Linguistics 37: 474-94. [CrossRef]

Kuhn, Thomas. 1962. The Historical Structure of Scientific Discovery. Science 136: 760-62. [CrossRef] [PubMed]

Lu, Min-Zhan, and Bruce Horner. 2013. Translingual Literacy, Language Difference, and Matters of Agency. College English 75: 586-611.

Mahala, Daniel. 1991. Writing Utopias: Writing Across the Curriculum and the Promise of Reform. College English 53: 773-89. [CrossRef]

Meierkord, Cristina. 2004. Syntactic variation in interactions across international Englishes. English World-Wide 25: 109-32. [CrossRef]

Nowacek, Rebecca S. 2011. Agents of Integration: Understanding Transfer as a Rhetorical Act. Carbondale: Southern Illinois University Press.

Pennycook, Alastair. 2008. English as a Language Always in Translation. European Journal of English Studies 12: 33-47. [CrossRef]

Pennycook, Alastair. 2010. Language as a Local Practice. London: Routledge.

Joseph Petraglia, ed. 1995. Reconceiving Writing, Rethinking Writing Instruction. Mahwah: Erlbaum.

Rankin, Elizabeth. 1990. From Simple to Complex: Ideas of Order in Assignment Sequences. Journal of Advanced Composition 10: 126-35. 
Rose, Mike. 1985. The Language of Exclusion: Writing Instruction at the University. College English 47: 341-59. [CrossRef]

Rubdy, Rani, and Mario Saraceni. 2006. Introduction. In English in the World: Global Rules, Global Roles. Edited by Rani Rubdy and Mario Saraceni. London: Continuum, pp. 5-16.

Selfe, Cynthia L. 2009. The Movement of Air, the Breath of Meaning: Aurality and Multimodal Composing. College Composition and Communication 60: 616-63.

Selfe, Cynthia L. 2010. Response to Doug Hesse. College Composition and Communication 61: 606-10.

Sifakis, Nikos. 2006. Teaching EIL—teaching international or intercultural English? What teachers should know. In English in the World: Global Rules, Global Roles. Edited by Rani Rubdy and Mario Saraceni. London: Continuum, pp. 151-68.

Smit, David W. 2004. The End of Composition Studies. Carbondale: Southern Illinois University Press.

Soliday, Mary. 2002. The Politics of Remediation: Institutional and Student Needs in Higher Education. Pittsburgh: University of Pittsburgh Press.

Trask, Haunani-Kay. 1987. From a Native Daughter. In The American Indian and the Problem of History. Edited by Calvin Martin. Oxford: Oxford University Press, pp. 171-78.

Trimbur, John. 1991. Literacy and the Discourse of Crisis. In The Politics of Writing Insturction: Postsecondary. Edited by Richard Bullock, John Trimbur and Charles Schuster. Portsmouth: Boynton/Cook Heinemann, pp. 277-95.

Tsing, Anna Lowenhaupt. 2005. Friction: An Ethnography of Global Connection. Princeton: Princeton University Press.

Yancey, Kathleen Blake. 2004. Made Not Only in Words: Composition in a New Key. College Composition and Communication 56: 297-328. [CrossRef]

Yancey, Kathleen Blake, Liane Robertson, and Kara Taczak. 2014. Writing across Contexts: Transfer, Composition, and Sites of Writing. Logan: Utah State University Press.

(C) 2017 by the author. Licensee MDPI, Basel, Switzerland. This article is an open access article distributed under the terms and conditions of the Creative Commons Attribution (CC BY) license (http:/ / creativecommons.org/licenses/by/4.0/). 